\title{
Aplikasi Sistem Administrasi Pada Yayasan Insan Mulia Sejahtera
}

\author{
Lia Nurul Fitriani ${ }^{1}$, Sri Mardiyati ${ }^{2}$, Halimatusha'diah ${ }^{3}$ \\ Program Studi Teknik Informatika, Fakultas Teknik dan Ilmu Komputer, \\ Universitas Indraprasta PGRI \\ Jalan Raya Tengah No 80, Kelurahan Gedong, Pasar Rebo, Jakarta Timur \\ lianurulfitriani@gmail.com,srimardiyati05@gmail.com, halimatushadiah31@gmail.com
}

\begin{abstract}
Abstrak
Tujuan perancangan aplikasi ini adalah untuk mempermudah pengolahan data administrasi yang terdapat pada Yayasan Insan Mulia Sejahtera, selain itu peneliti berharap perancangan sistem ini dapat membantu menyelesaikan permasalahan yang timbul akibat tidak adanya sistem komputerisasi serta dapat meningkatkan kinerja pengurus dalam melaksanakan tugas-tugasnya. Metode penelitian yang digunakan dalam perancangan sistem informasi ini adalah studi lapangan yang memuat dua unsur yaitu pengamatan atau observasi dan wawancara dengan pihak terkait untuk mendapatkan informasi secara langsung di lapangan. Selain itu peneliti juga melakukan penelitian dengan menggunakan metode kepustakaan berdasarkan referensi dari berbagai sumber media yang memuat informasi mengenai hal-hal yang berkaitan langsung dengan kebutuhan penelitian. Setelah dilakukan pengujian sistem secara komputerisasi ternyata aplikasi ini dapat membantu memenuhi kebutuhan pengurus dalam mengelola seluruh data administrasi pada Yayasan Insan Mulia Sejahtera.
\end{abstract}

Kata Kunci: Aplikasi, Sistem, Administrasi, Java, Netbeans

\begin{abstract}
The purpose of designing this application is to facilitate the processing of administrative data contained in the Yayasan Insan Mulia Sejahtera, in addition, the author hopes that the design of this system can help solve problems arising from the absence of computerized systems and can improve the performance of managers in carrying out their tasks. The research method used in the design of this information system is a field study that contains two elements, namely observation or observation and interviews with related parties to get information directly in the field. In addition, the author also conducts research using literature methods based on references from various media sources that contain information about matters directly related to research needs. After computerized system testing it turns out that this application can help meet the needs of administrators in managing all administrative data at the Insan Mulia Sejahtera Foundation.
\end{abstract}

Keyword: Application, System, Administration, Java, Netbeans

\section{PENDAHULUAN}

Teknologi infomasi dibutuhkan dalam mendapatkan, mengelola, mengumpulkan dan menganalisa data. Bidang usaha memiliki kaitan erat dengan teknologi informasi untuk mempermudah dan memajukan dunia usaha yang terus maju dan berkembang seiring berjalannya waktu, maka komputer pada saat ini telah dijadikan sebagai alat bantu untuk mempermudah dunia usaha. Informasi adalah hasil pengolahan data yang dapat memberikan makna atau arti dan berguna dalam meningkatkan kepastian (Darmawan\&Fauzi, 2013).

Yayasan Insan Mulia Sejahtera adalah sebuah yayasan sebagai wadah kepedulian berbagai pihak, yaitu berbagi kepada sesama manusia. Adapun sistem yang berjalan pada perusahaan ini yaitu transaksi yang terjadi pada bagian administrasi yang masih menggunakan sistem manual yang menggunakan Microsoft Excel, tidak jarang data yang dicatat sering mengalami data yang tidak akurat, sehingga resiko kemungkinan akan kehilangan data-data penting seperti laporan yang rusak dikarenakan tidak tersedianya media penyimpanan database, serta membutuhkan waktu yang lama dalam pencarian data yang dibutuhkan seperti data donasi dan data anak asuh.

Sistem merupakan suatu kumpulan dari komponen-komponen yang membentk satu kesatuan. Sebuah Organisasi dan sistem informasi adalah sistem fisik dan sosial yang ditata sedemikian rupa 
untuk mencapai tujuan tertentu (Tyoso, 2016). Administrasi adalah kegiatan perencanaan, pengendalian, dan pengorganisasian pekerjaan perkantoran, serta penggerakan mereka yang melaksanakannya agar mencapai tujuan yang telah ditetapkan.. (Bailah, 2019)

Berdasarkan permasalahan yang ada, maka peneliti mempunyai gagasan untuk menjadikan permasalahan tersebut sebagai bahan penelitian dan diusulkan untuk merancang sistem aplikasi administrasi berbasis java yang mendalam pembuatan aplikasi tersebut menggunakan menggunakan Netbeans IDE 8.0 dan MySQL untuk databasenya. Perancangan adalah sebuah proses untuk mendefinisikan sesuatu yang akan dikerjakan dengan menggunakan teknik yang bervariasi serta didalamnya melibatkan deskripsi mengenai arsitektur serta detail komponen dan juga keterbatasan yang akan dialami dalam proses pengerjaannya (Soetam, 2011). Java merupakan bahasa pemrograman yang dikembangan dari bahasa pemrograman $\mathrm{C}++$, Sehingga bahasa pemrograman ini seperti bahasa pemrograman C++ (Supardi, 2010)Netbeans Merupakan sebuah aplikasi Integrated Development Environment (IDE) yang Menggunakan Bahasa Pemograman Java dari Sun Microsystems yang berjalan diatas swing (Nofriadi, 2014). MySQL merupakan RDBMS (atau server database) yang mengelola database dengan cepat menampung dalam jumlah sangat besar dan dapat di akses oleh banyak (Raharjo, 2011). Dengan adanya sistem terkomputerisasi ini diharapkan dapat memudahkan dalam administrasi pada yayasan tersebut.

\section{PENELITIAN RELEVAN}

Dalam rangka mendapatkan hasil penelitian yang baik, selain melakukan penelitian secara langsung peneliti juga melakukan kajian pustaka dari hasil penelitian yang telah dilakukan, beberapa hasil acuan yang menjadi acuan adalah : Penelitian oleh Shaff Barest Valety dengan judul penelitian "Perancangan Sistem Administrasi Pada PT Indo Media Persada Berbasis Java". Sistem yang digunakan sebelumnya kurang efisien sehingga membutuhkan waktu yang lama dalam pengerjaan dan pencarian data serta kurang efisien dan efektif dalam mengolah data. Hasil penelitian tersebut dengan adanya sistem ini PT. Indo Media Persada menjadi terbantu karena mempermudah dalam pengolahan data dan dalam proses pengarsipan.

\section{METODE PENELITIAN}

Melakukan penelitian diperlukan suatu metode penelitian yang sesuai dengan pokok permasalahan yang akan diteliti. Metode Penelitian pada dasarnya merupakan cara ilmiah untuk mendapatkan data dengan tujuan dan kegunaan tertentu (Sugiyono, 2013). Metode penelitian yang digunakan oleh peneliti adalah metode grounded research yaitu suatu metode penelitian berdasarkan pada fakta dan menggunakan analisis perbandingan dengan tujuan mengadakan generalisasi empiris, menetapkan konsep, membuktikan teori, mengembangkan teori, pengumpulan dan analisis data dalam waktu yang bersamaan.

Metode Pengumpulan Data yang digunakan adalah :

\section{Studi Pustaka}

Studi pustaka dilakukan dengan mencari referensi dari beberapa buku dan jurnal yang berhubungan dengan sistem aplikasi administrasi.

2. Studi Lapangan

Dalam studi ini peneliti melakukan untuk melihat secara langsung kegiatan atau penerapan sistem dalam menghasilkan hasil analisa dari Yayasan Insan Mulia Sejahtera. Dalam studi ini memakai teknik pengumpulan data dengan cara:

a. Observasi

Observasi merupakan proses pengamatan sistematis dari aktivitas manusia dan pengaturan fisik dimana kegiatan tersebut berlangsung secara terus menerus dari lokus aktivitas bersifat alami untuk menghasilkan fakta (Hasanah, 2017) Survei secara langsung ini dilakukan pada bulan Maret 2020 di Yayasan Insan Mulia Sejahtera Jakarta Selatan untuk melihat dan mengamati secara langsung proses kegiatan yang dilakukan oleh yayasan.

b. Wawancara 
Peneliti tidak hanya melakukan pengamatan langsung, tetapi juga peneliti melakukan wawancara langsung dengan ketua umum yayasan untuk memperoleh dan memperjelas data dan informasi yang telah peneliti dapatkan melalui metode observasi terutama yang berkaitan dengan sistem aplikasi administrasi. Pada kegiatan wawancara ini peneliti mengajukan beberapa pertanyaan yaitu mempertanyakan mengenai bagaimana proses administrasi pada yayasan.

\section{HASIL DAN PEMBAHASAN}

\section{Analisis Permasalahan}

Terdapat beberapa kendala dalam proses penjadwalan dan pengelolaan data Yayasan Insan Mulia Sejahtera, salah satunya adalah saat ini sistem pendukung keputusan dalam penjadwalan dan pengelolaan data yang dilakukan masih bersifat manual, sehingga dirasakan kurang optimal. Untuk memudahkan pihak Yayasan Insan Mulia Sejahtera peneliti membuat program sistem menggunakan UML untuk merancang sistem ini.

\section{Alternatif Penyelesaian Masalah}

Tahap pemecahan masalah merupakan tahap tindak lanjut dari permasalahan sistem yang ada sebelumnya. Dari beberapa kelemahan yang ada dalam sistem diharapkan dapat dieliminasi melalui alternatif sistem seperti mempergunakan sistem berbasis komputer, dipergunakan teknik pengolahan data yaitu database sistem yang memungkinkan pemakai dapat meminta informasi dan file setiap saat tanpa menunggu lama dari jenis informasinya yang diminta atau yang dibutuhkan. Memberikan sosialisasi atau penyuluhan secara detail kepada pengguna sistem agar memudahkan pengguna dalam penggunaan sistem administrasi keuangan berbasis komputer ini.

\section{UML Sistem yang Diusulkan}

UML (Unified Modelling Language) adalah salah satu standar bahasa yang banyak digunakan didunia industri untuk mendefinisikan requirement, membuat analisis dan desain, serta menggambarkan arsitektur dalam pemrograman berorientasikan objek. (A.S., Rosa dan Shalahuddin, 2016)

\section{a. Use Case Diagram}

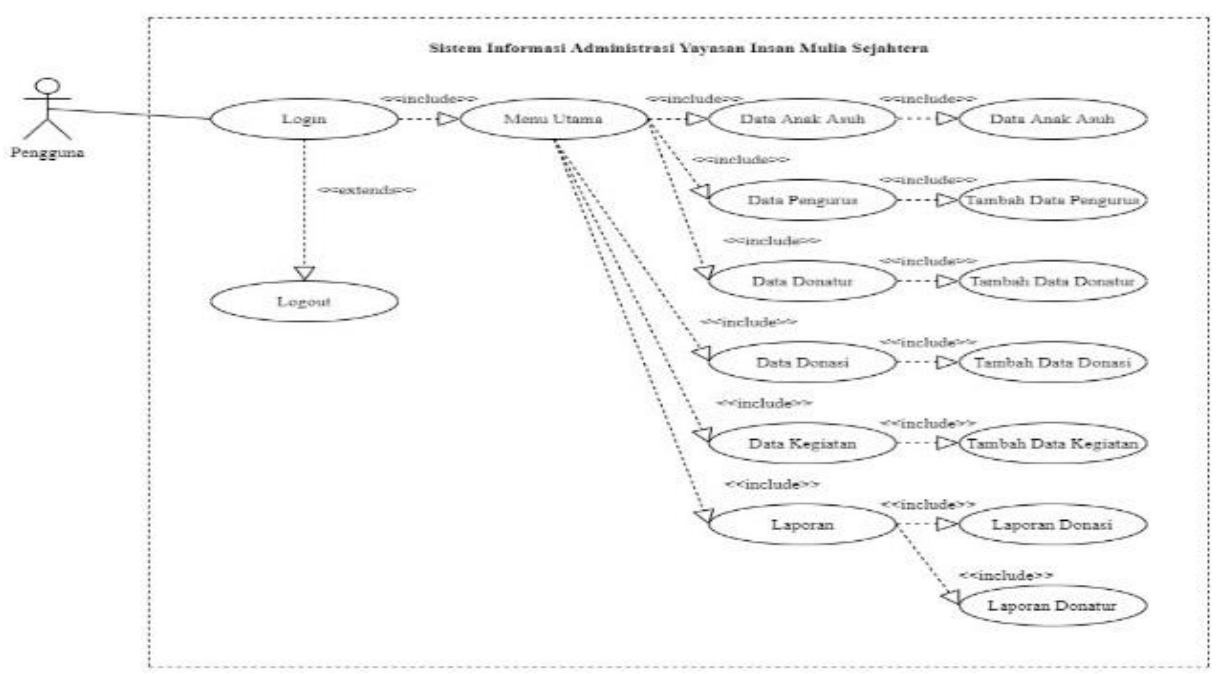

Gambar 1. Use Case Diagram

\section{b. Activity Diagram}




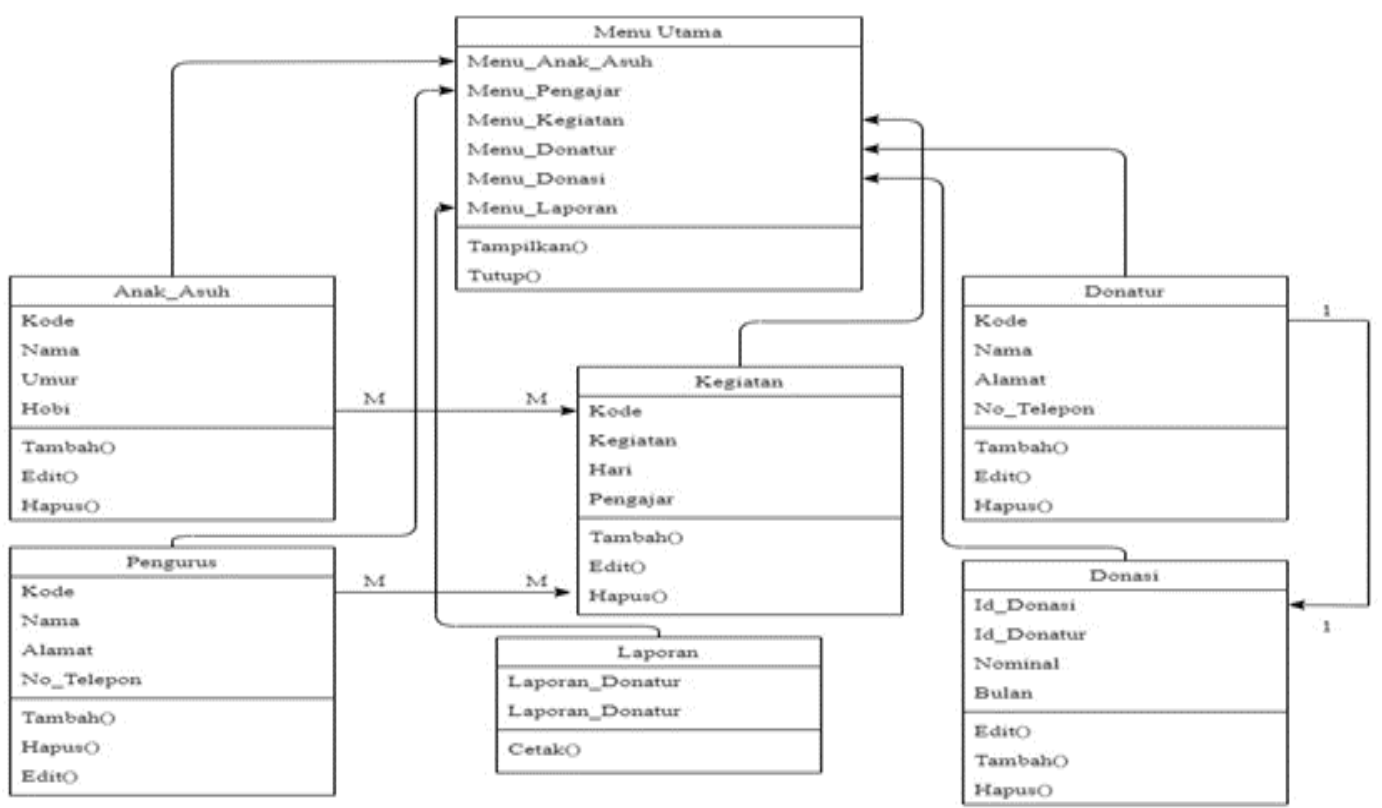

Gambar 2. Class Program

\section{Tampilan Aplikasi}

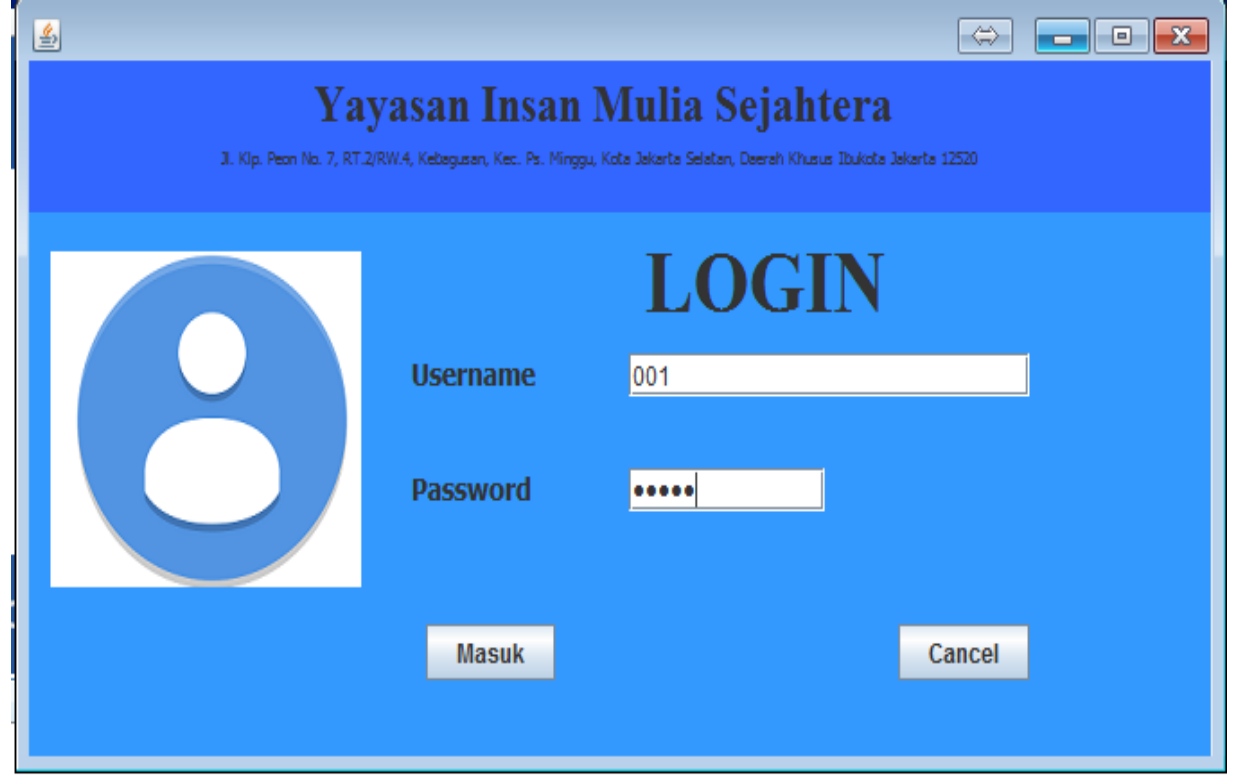

Gambar 3. Menu Login

Pada tampilan layar di atas merupakan tampilan menu login, terdapat form yang harus diisi oleh user yaitu username dan password. 


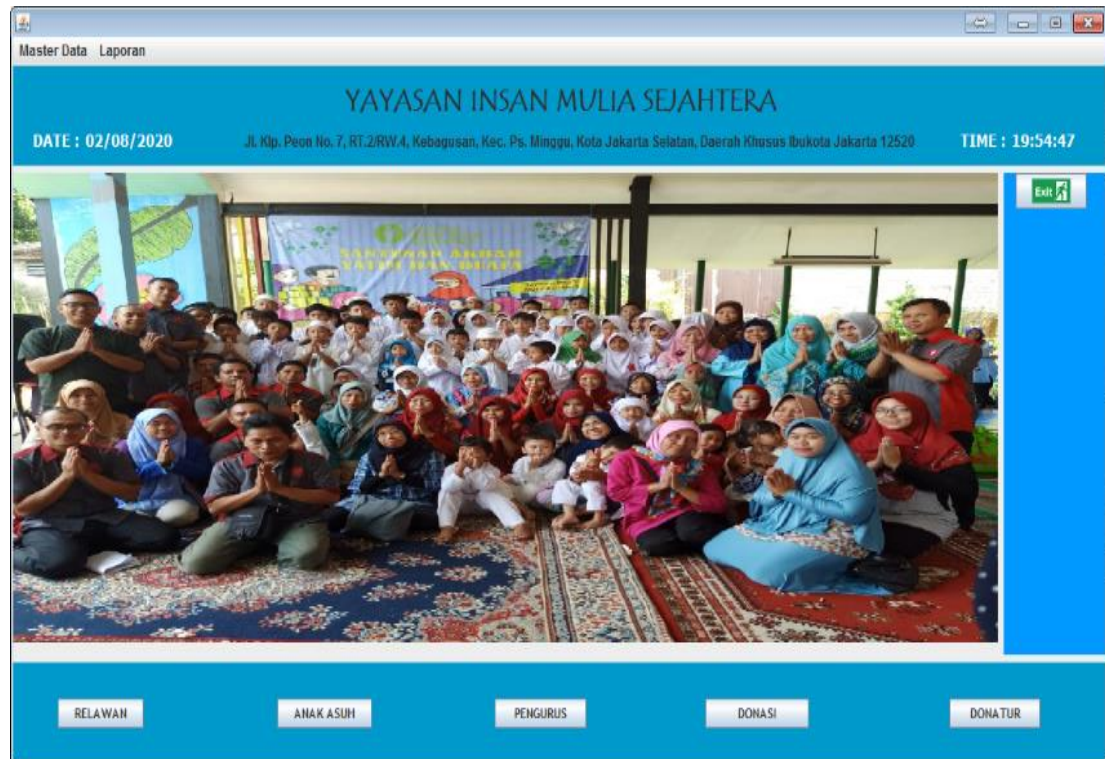

Gambar 4. Menu Utama

Setelah user melakukan login akan dialihkan pada menu utama yang terdapat menu-menu untuk melakukan transaksi.

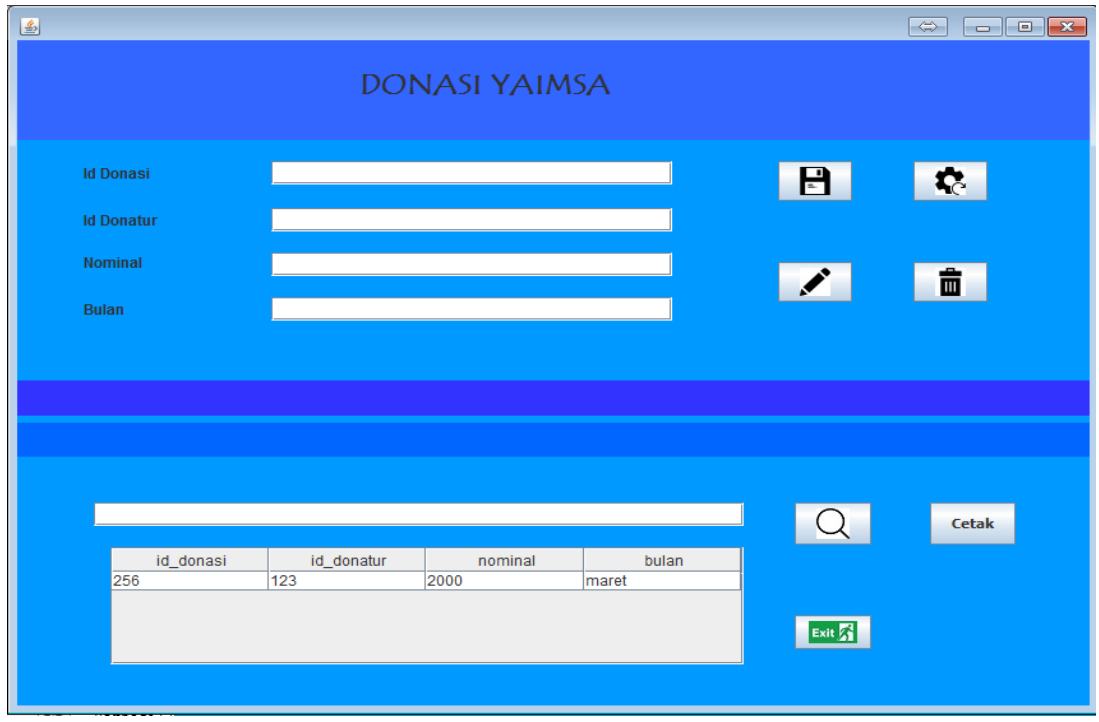

Gambar 5. Tampilan Data Donasi

Tampilan di atas merupakan tampilan data donasi yang masuk setiap bulannya. 


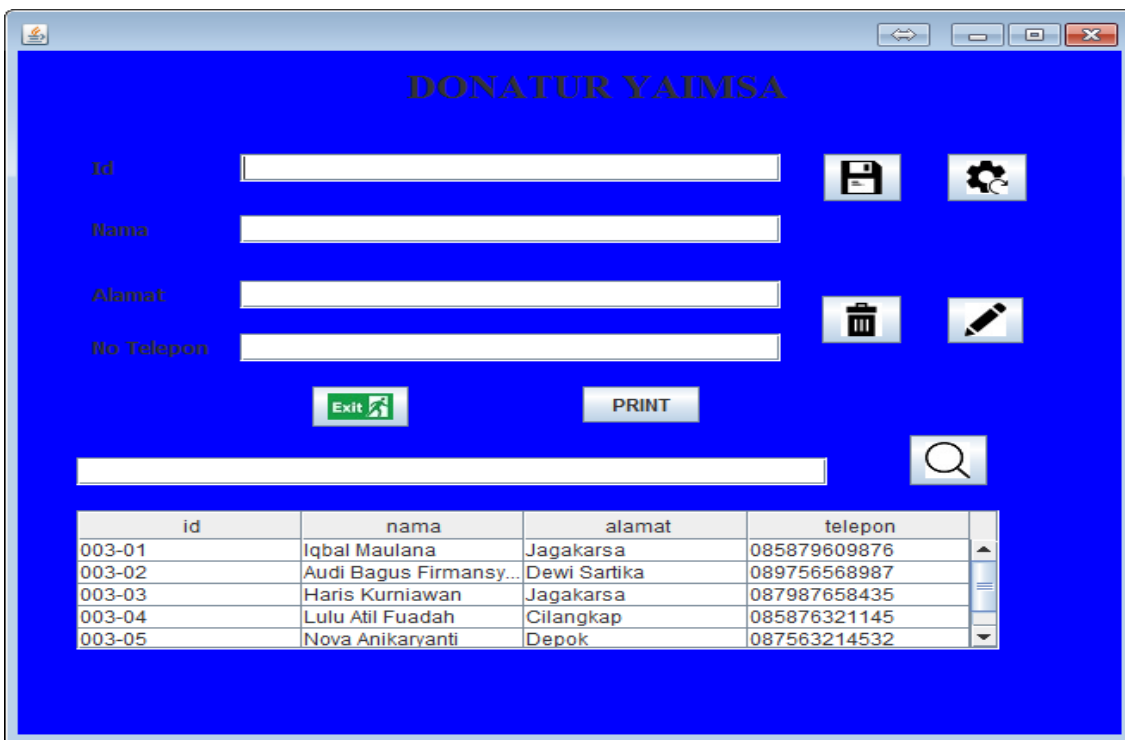

Gambar 6. Tampilan Data Donatur

Tampilan di atas merupakan tampilan data donatur yang yang telah berdonasi.

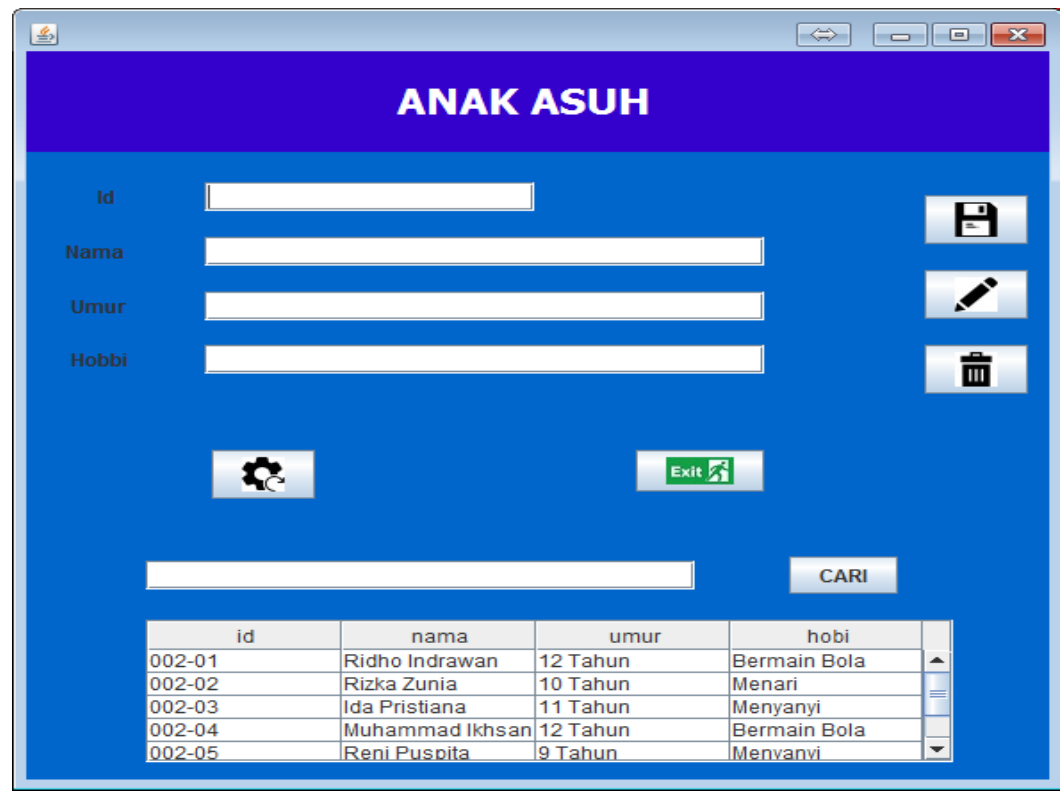

Gambar 7. Tampilan Data Anak Asuh

Tampilan di atas merupakan tampilan data anak asuh yang berada pada yayasan. 


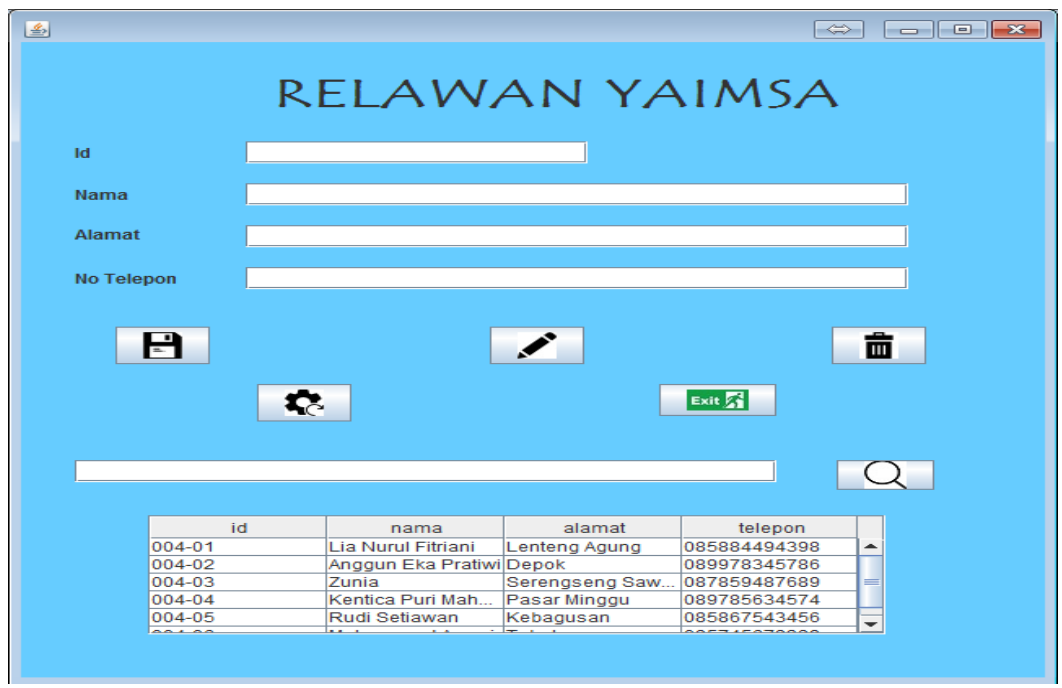

Gambar 8. Tampilan Data Relawan

Tampilan di atas merupakan tampilan data relawan yang membantu berjalannya sistem.

\section{SIMPULAN}

Dengan dibuatnya aplikasi sistem administrasi pada Yayasan Insan Mulia Sejahtera, dapat ditarik beberapa kesimpulannya adalah aplikasi sistem administrasi ini dirancang dengan menggunakan bahasa pemrograman java pada software Netbeans IDE 8.2 dengan basis data MySQL untuk mempermudah pengolahan data administrasi pada Yayasan Insan Mulia Sejahtera. Dengan adanya aplikasi sistem administrasi maka kinerja pengurus yayasan dapat menjadi lebih efektif dan efisien serta meningkatkan layanan administrasi pada Yayasan Insan Mulia Sejahtera.

\section{DAFTAR PUSTAKA}

A.S., Rosa dan Shalahuddin, M. (2016). Rekayasa Perangkat Lunak Terstruktur dan Berorientasi Objek. In Informatika Bandung.

Darmawan dkk. (2013). Sistem Informasi Manajemen. Bandung: PT Remaja Rosdakarya.

Bailah, B. (2019). Implementasi Tujuan Jangka Menengah Dan Jangka Panjang Proyek Perubahan Oleh Camat Alumni Diklat Kepemimpinan Tingkat III di Kota Jambi. Jurnal Sains Sosio Humaniora, 3(2), 151-166.

Nofriadi. (2015). Java Fundamental dengan Netbeans 8.0.2. Yogyakarta: Deepublish.

Hasanah, H. (2017). Teknik-teknik observasi (sebuah alternatif metode pengumpulan data kualitatif ilmu-ilmu sosial). AtTaqaddum, 8(1), 21-46.

Raharjo, Budi. (2011). Belajar Otodidak Menggunakan Mysql:Studi Kasus Membuat Toko Buku Online. Bandung: Informatika.

Soetam, Rizky. (2011). Konsep Dasar Rekayasa Perangkat Lunak. Jakarta: Prestasi Pustaka.

Sugiyono. (2011). Metodelogi Penelitian Kuantitatif, Kualitatif Dan R\&D. Bandung: ALFABETA.

Supardi. (2010). Semua Bisa Menjadi Programmer Java Basic Programming. Jakarta: PT Elex Media Komputindo Tyoso, J. S. P. (2016). Sistem Informasi Manajemen. Deepublish. 